\title{
Acúmulo, exportação e restituição de nutrientes pelas bananeiras "Prata Anã" e "Grand Naine”
}

\author{
Accumulation, export and restitution of nutrients by 'Prata Anã' and 'Grand Naine' bananas
}

\author{
Frederico Antonio Loureiro Soares ${ }^{\mathrm{I}}$ Hans Raj Gheyi ${ }^{\mathrm{II}}$ Fábio Henrique Tavares de Oliveira ${ }^{\mathrm{III}}$ \\ Pedro Dantas Fernandes ${ }^{\text {II }}$ Allan Nunes Alves ${ }^{\text {II }}$ Francisco Valfisio da Silva $^{\text {IV }}$
}

\section{- NOTA-}

\section{RESUMO}

Conhecer o estado nutricional da parte colhida das plantas é importante para se analisar a qualidade do produto e a remoção de nutrientes da área de cultivo. Com tal objetivo, realizou-se este trabalho, visando-se avaliar os nutrientes exportados (engaço + frutos) e os restituídos ao solo de um bananal, no primeiro ciclo de produção. A pesquisa foi realizada entre junho/2004 e maio/2005 em um Cambissolo, em Limoeiro do Norte-CE, onde foram plantados dois blocos de amostragens com as cultivares "Grand Naine" e "Prata Anã". A partir do 30 dia após plantio e a cada 45 dias, foram amostradas e separadas, em suas diversas partes, as plantas de quatro touceiras, escolhidas aleatoriamente, para análise. A exportação de nutrientes pelo cacho da cultivar "Prata Anã" foi em ordem $K>N>C a>P>M g$, enquanto para a cultivar "Grand Naine" a seqüência foi $K>C a>N>$ $P>M g$. Por ocasião da colheita, na touceira da "Prata Anã”, foram acumulados, em média, 2,2 vezes mais nutrientes, comparada com a planta mãe, enquanto na "Grand Naine" essa relação, em média, foi de 1,2. Independente da cultivar, a ordem decrescente da quantidade de nutrientes restituídos ao solo foi $K>C a>N>M g>P$.

Palavras-chave: Musa sp, nutrição mineral, matéria seca.

\section{ABSTRACT}

The knowledge about the content of nutrients in the harvested part of plants is important to assess the quality of product and the removal of the nutrients from the cultivated area. This research was carried out to evaluate the nutrients exported (rachis of the inflorescence + fruits), and restituted to the soil, in a banana plantation. The study was conducted during the period of June, 2004 to May, 2005, in an Inceptisol, in the municipality of Limoeiro do Norte, Ceará, where two blocks of samplings were planted with 'Grand Naine' and 'Prata Anã' cultivars. Starting from the 30 days after planting, at 45 days interval, plant samples were collected, harvesting four clumps in full competition, chosen at random for analysis. The sequence of nutrients exported by the bunch in case of 'Prata Anã' was $K>N>C a>P>M g$ while in Grand Naine cultivar the sequence was of $\mathrm{K}>\mathrm{Ca}>\mathrm{N}>\mathrm{P}>\mathrm{Mg}$. At harvest time, in the clumps of cv. Prata Anã were accumulated on an average 2.2 times more nutrients in comparison to mother plant while in the plants of Grand Naine such relation was 1.2 times. Independent of cultivar, the order of the amount of nutrients returned to the soil after the crop removal was $K>C a>N>M g>P$.

Key words: Musa sp, mineral nutrition, dry matter.

A bananeira ocupa 494.460ha de área no Brasil, sendo o terceiro produtor mundial (6,7 milhões toneladas) (IBGE, 2005). A região Nordeste produz cerca de 35\% da produção nacional de bananas, com destaques para BA, CE e RN. A região da Chapada do Apodi, entre os Estados do CE e RN, tem se destacado no cultivo de bananeira, com uma produção de 365.181t, em 42.229ha de área plantada.

'Faculdade de Tecnologia (CENTEC), Sobral, CE, Brasil.

"Unidade Acadêmica de Engenharia Agrícola (UAEAg/UFCG), CP 10078, 58109-970, Campina Grande, PB, Brasil. E-mail: hans@deag.ufcg.edu.br. Autor para correspondência.

II'Departamento de Solos e Engenharia Rural, Centro de Ciências Agrárias (CCA/UFPB). Campus Universitário, Areia, PB, Brasil.

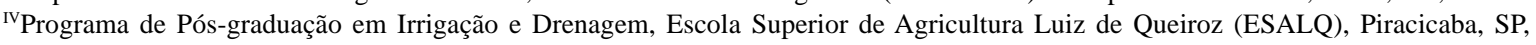
Brasil. 
No Brasil, a produtividade da bananeira é baixa por equívocos do produtor que, muitas vezes, só se preocupa em adubar para suprir as necessidades nutricionais da planta-mãe, sendo insuficiente o suprimento de nutrientes durante todo o ciclo de produção da planta (BORGES et al., 1999).

Nesse sentido, o estudo da marcha de crescimento e de absorção de nutrientes possibilita conhecer a demanda nutricional em diferentes fases fenológicas da planta. LAHAV \& TURNER (1983) já enfatizavam que a distribuição de nutrientes na planta depende da quantidade total presente no solo, associada à sua disponibilidade e taxa de liberação. VITTI \& RUGGIERO (1984) ressaltam que, além do conhecimento do conteúdo total de nutrientes absorvidos pela bananeira, é oportuno conhecer a percentagem exportada com a colheita, visando a sua reposição no solo. Os nutrientes contidos no material vegetal restituído ao solo são importantes pelas quantidades nele existentes, atendendo os ciclos subseqüentes e reduzindo a quantidade de adubos a ser fornecida às plantas.

Neste estudo, objetivou-se avaliar a quantidade de nutrientes (N, P, K, Ca e Mg) acumulada em várias fases de desenvolvimento das plantas e a restituída ao solo na forma de resíduos, bem como a exportada pelos cachos, por ocasião da colheita, no final do primeiro ciclo de produção da bananeira.

O experimento foi conduzido no período de junho de 2004 a maio de 2005, em uma propriedade agrícola da empresa Fazenda Frutacor Ltda, situada no Perímetro Irrigado do Jaguaribe, na Chapada do Apodi (508'45” S, 3805'52” W, altitude 70m), município de Limoeiro do Norte-CE, em um Cambissolo (pH - 7,7; P $36 \mathrm{mg} \mathrm{dm}^{-3}$; Ca e $\mathrm{Mg}$ - 8,8 e 2,7 $\mathrm{cmol} \mathrm{kg}^{-1}$, textura Franco argilo siltosa)

O trabalho constou de dois blocos de amostragens (18m de largura e 75m de comprimento), um com a cv. "Prata Anã” e outro com a "Grand Naine”, composto de seis fileiras de 30 plantas. As mudas foram plantadas no espaçamento de 4,0m entre fileiras duplas, $2,0 \mathrm{~m}$ entre fileiras simples e $2,5 \mathrm{~m}$ entre plantas nas fileiras (1333 plantas ha-1). O bananal foi conduzido com uma planta-mãe e um rebento (planta-filha) por cova, formando a touceira.

O preparo do solo constou de aração e duas gradagens, seguidas da abertura de covas. Em fundação, foram aplicados 5L de esterco e 3,0, 6,6 e 8,3g por cova de $\mathrm{N}, \mathrm{P}$ e K, respectivamente, tendo como fontes os adubos mono-amônio fosfato (MAP) e sulfato de potássio. A partir de 30 dias após plantio, foram aplicados, a cada três dias, via fertirrigação, uréia, sulfato de potássio e cloreto de potássio, fornecendo, respectivamente, 277 e $538 g$ por planta de $\mathrm{N}$ e K, durante o primeiro ciclo. O manejo cultural consistiu de controle de pragas, doenças e de plantas daninhas e as irrigações constaram de 75L por touceira, diariamente, por gotejamento com cinco emissores por touceira, em dois turnos de dois horas.

A partir dos 30 DAP, a cada 45 dias foram coletadas, aleatoriamente, as plantas de quatro touceiras; após corte, as plantas eram separadas em rizoma, pseudocaule, limbo foliar, pecíolo, engaço e frutos; em seguida, após lavagem, foram retiradas subamostras de cada parte, para secagem em estufa de ventilação forçada à temperatura de $65^{\circ} \mathrm{C}$ (TWYFORD \&WALMSLEY, 1974).

Na matéria seca das partes da planta, foram determinados os teores de N, P, K, Ca e Mg (SILVA, 1999). A partir dos dados, foi calculado o conteúdo de nutrientes nos diversos órgãos da planta-mãe e da planta-filha e, conseqüentemente, da touceira e a quantidade de nutrientes restituídos ao solo por meio da devolução dos resíduos vegetais da planta-mãe.

O acúmulo de matéria seca (MS) da touceira, inicialmente lento, foi crescente no restante do ciclo. No final do ciclo da cv. "Prata Anã” (345 DAP) e da cv. "Grand Naine” (300 DAP), a produção de MS foi estimada em 17,14 e 9,74t ha-1 ${ }^{-1}$, respectivamente, com participação da planta-mãe de 48,4 e 85,5\% da fitomassa (Figura 1). O maior acúmulo de MS na touceira da Prata Anã ocorreu no período de 300 a 345 DAP, quando a taxa de incremento foi de $86,2 \mathrm{~kg} \mathrm{ha}^{-1} \mathrm{dia}^{-1} \mathrm{e} \mathrm{na} \mathrm{cv}$. "Grand Naine”, dos 165 aos 210 DAP, com taxa de 98,0kg ha-1 dia $^{-1}$. A planta-mãe também acumulou MS de forma crescente, porém, em ambas as cultivares, a partir dos 255 DAP, o crescimento da MS se estabilizou até a colheita. Nota-se (Figura 1) que a cv. "Prata Anã" restituiu ao solo, na época de colheita, 70,2\% e a "Grand Naine” 48,6\% da MS total da planta-mãe, uma evidência que na cv. "Grand Naine” a maior parte dos produtos fotoassimilados é translocada para os frutos. Como na época de colheita, a quantidade de MS acumulada na planta-filha (diferença entre a touceira e planta-mãe) da cv. "Prata Anã" foi 51,6\% e na cv. "Grand Naine" esse valor foi de 14,5\% (Figura 1) é notória a necessidade de que a adubação na cultura da bananeira, sobretudo no caso de "Prata Anã", deve satisfazer não só a demanda de nutrientes da planta-mãe, como também a da planta-filha, concordando com OLIVEIRA et al. (2005).

$\mathrm{O}$ acúmulo de $\mathrm{N}$ na touceira foi crescente até o final do ciclo, com máximo de 148,6 e 102,3kg ha"-1, na planta da cv. "Prata Anã” e na "Grand Naine”, respectivamente (Figura 1); na planta-mãe, a acumulação máxima se deu aos 255 DAP, com 91,1 e 

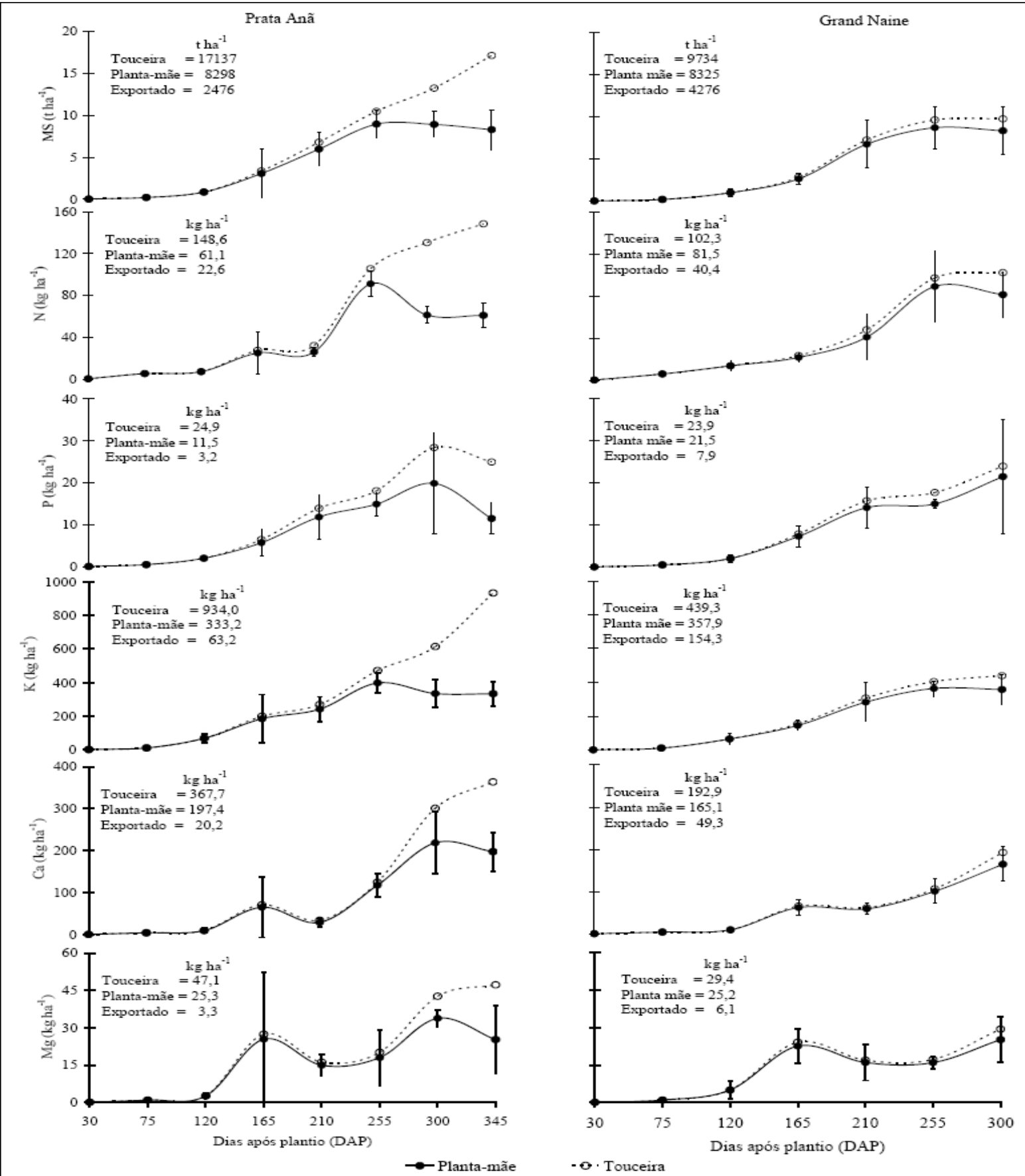

Figura 1 - Acúmulo de matéria seca, nitrogênio, fósforo, potássio, cálcio e magnésio para a planta-mãe e a touceira das bananeiras Prata Anã e Grand Naine durante o primeiro ciclo de produção. Obs.: os dados inseridos em cada gráfico se referem aos valores de nutrientes determinados nas partes da planta, por ocasião da colheita.

89,2kg ha-1 , representando 86,4 e 91,7\% do conteúdo total de N na touceira, para as cultivares Prata Anã e Grand Naine, respectivamente.

Com produtividades de $12,99 \mathrm{t} \mathrm{ha}^{-1}$ de bananas da cv. "Prata Anã" e de 28,72t ha" de "Grand Naine” (Figura 1), as quantidades de $\mathrm{N}$ exportadas pela colheita foram 22,6kg ha-1 $(36,87 \%)$ e $40,4 \mathrm{~kg} \mathrm{ha}^{-1}$ (49,59\%), notando-se que a cv. "Grand Naine" acumula quase duas vezes mais $\mathrm{N}$ no cacho que a cv. "Prata Anã". A planta-mãe restituiu ao solo 63,2 e 50,4\% de N acumulado na cv. "Prata Anã" e "Grand Naine", respectivamente. A quantidade de $\mathrm{N}$ da cv. "Grand 
Naine” (41,1 $\left.\mathrm{kg} \mathrm{ha}^{-1}\right)$ que pode retornar ao solo foi ligeiramente superior à registrada por FARIA (1997), que encontrou um conteúdo de $38,4 \mathrm{~kg} \mathrm{ha}^{-1}$ desse nutriente. Na cv. "Prata Anã", os valores encontrados neste estudo $\left(38,6 \mathrm{~kg} \mathrm{ha}^{-1}\right)$ foram inferiores aos do referido autor $\left(92,1 \mathrm{~kg} \mathrm{ha}^{-1}\right)$.

O fósforo (P) foi o nutriente menos absorvido, com máximo de 24,9 e 23,9kg ha-1, pela cv. "Prata Anã” e "Grand Naine”, respectivamente, dos quais 46,1 e $89,7 \%$ se encontravam na planta-mãe (Figura 1). O conteúdo de $\mathrm{P}$ foi crescente até os 300 DAP, diminuindo após esta data, na planta-mãe, devido à sua translocação para o fruto (Figura 1). Na colheita, a quantidade de $\mathrm{P}$ exportada foi de $3,2 \mathrm{~kg} \mathrm{ha}^{-1}$ pela "Prata Anã" e 7,9kg ha-1 pela "Grand Naine"; portanto, a adubação do segundo ciclo da cv. "Prata Anã” deve ser menor (Figura 1). FARIA(1997) encontrou valores maiores de exportação de $\mathrm{P}$ que os observados neste experimento, cerca de 66,5\% pela cv. "Grand Naine” e 44,4\% na cv. "Prata Anã”, enquanto neste trabalho a exportação de P pelo cacho foi de 28,3 e 36,9\% para as cultivares "Prata Anã” e “Grand Naine”, respectivamente.

A planta-mãe da cv. "Prata Anã” restituiu, ao solo, 72,2\% do total de P, já a cv. "Grand Naine” restituiu 63,3\%. Como os solos da região semi-árida nordestina têm alta capacidade de fixação deste elemento, tal incorporação de resíduos vegetais é benéfica, concordando com MOREIRA (1999).

O potássio (K) foi o nutriente mais absorvido pelas touceiras de plantas, com acúmulo máximo de 934,1 kg ha-1 nas plantas da cv. "Prata Anã” e 439,3kg ha $^{-1}$ nas de "Grand Naine” (Figura 1), sendo que, na época de colheita, 35,7 e 81,5\% de K se encontravam, respectivamente, na planta-mãe. Por ocasião da colheita, a planta-mãe da cv. "Prata Anã” tinha acumulado 333,2 $\mathrm{kg} \mathrm{ha}^{-1}$ de $\mathrm{K}$, sendo maior esse valor nas bananeiras "Grand Naine”, cerca de 357,9kg ha-1 de $\mathrm{K}$; dessas quantidades foram exportados, respectivamente, 63,2 e 154,3kg ha-1. Portanto, as plantas da cv. "Prata Anã” restituíram ao solo 81,0\% e a "Grand Naine” 56,9\% do total absorvido.

Até os 255 DAT, a acumulação de Ca na planta-mãe e na touceira, em ambas as cultivares, foi praticamente idêntico (Figura 1). Na época de colheita, foram registrados 197,4 e 165,1 $\mathrm{kg} \mathrm{ha}^{-1}$ de Ca acumulado na planta-mãe da cv. "Prata Anã" e "Grand Naine”, respectivamente. A exportação do nutriente também variou entre os genótipos, com totais de 20,2 e 49,3kg ha $^{-1}$, com restituição ao solo através dos resíduos vegetais da planta-mãe de 89,8 e 70,1\% de Ca, respectivamente (Figura 1). FARIA (1997) observou quantidades menores de exportação dessas mesmas cultivares, sendo essa diferença provavelmente devido ao alto teor de cálcio presente no solo usado neste experimento (Figura 1).

O magnésio foi o segundo macronutriente menos absorvido pelas plantas. Na época de colheita, 53,7 e 85,7\% do Mg da touceira se achavam na plantamãe da cv. "Prata Anã" e "Grand Naine", respectivamente. A quantidade de Mg exportada pela cv. "Prata Anã" foi de 3,3kg ha-1 e 6,1 kg ha-1 pela cv. "Grand Naine”. A exportação de Mg em plantas de "Prata Anã” e "Grand Naine”, neste experimento, foram superiores aos valores de 11,3 e 17,0\% encontrados por FARIA (1997), respectivamente, para os mesmos genótipos.

Os totais de nutrientes exportados pela cv. "Prata Anã” foram: K (63,6kg ha-1 $)>\mathrm{N}\left(22,5 \mathrm{~kg} \mathrm{ha}^{-1}\right)>$ Ca $\left(20,2 \mathrm{~kg} \mathrm{ha}^{-1}\right)>\operatorname{Mg}\left(3,3 \mathrm{~kg} \mathrm{ha}^{-1}\right)>\mathrm{P}\left(3,2 \mathrm{~kg} \mathrm{ha}^{-1}\right)$; na cv. "Grand Naine” as quantidades foram: K (154,3kg ha $\left.^{-1}\right)>$ Ca $\left(49,3 \mathrm{~kg} \mathrm{ha}^{-1}\right)>\mathrm{N}\left(40,4 \mathrm{~kg} \mathrm{ha}^{-1}\right)>\mathrm{P}\left(7,9 \mathrm{~kg} \mathrm{ha}^{-1}\right)$ $>\operatorname{Mg}\left(6,1 \mathrm{~kg} \mathrm{ha}^{-1}\right)$. Portanto, as cultivares têm exigências nutricionais e padrão de partição de nutrientes diferentes; assim, as plantas devem ser adubadas de forma diferenciada, contrário à prática em uso na região. Considerando que o solo e a água fornecem quantidades suficientes de Ca, torna-se imprescindível a reposição de K e N com mais freqüência na área de cultivo, por meio de adubações, visando não somente à demanda nutricional da planta-mãe, mas também à da touceira. Com relação aos demais nutrientes (Mg e P), não há necessidades dessa reposição com a mesma freqüência de $\mathrm{Ke} \mathrm{N}$.

\section{AGRADECIMENTOS}

À Fazenda Frutacor Ltda, na pessoa do proprietário Sr. João Teixeira por proporcionar infra-estrutura necessária e ao Conselho Nacional de Desenvolvimento Científico e Tecnológico (CNPq), pelo apoio financeiro para realização da pesquisa.

\section{REFERÊNCIAS}

BORGES, A.L. et al. Solos, nutrição e adubação. In: ALVES, E.J. (Ed.). A cultura da banana: aspectos técnicos, socioeconômicos e agroindustriais. Brasília: Embrapa, 1999. p.197-260.

FARIA, N.G. Absorção de nutrientes por cultivares e híbridos promissores de bananeira. 1997. 66p. Dissertação (Mestrado) - Curso de Pós-graduação em Agronomia, Universidade Federal da Bahia. 
IBGE - INSTITUTO BRASILEIRO DE GEOGRAFIA E ESTATÍSTICA. Produção agrícola municipal. 2005. Capturado em 17 abr. 2007. On line. Disponível na internet: http://www.sidra.ibge.gov.br/bda/tabela/protabl.asp?z=p\&o=11.

LAHAV, E.; TURNER, D.W. Banana nutrition. Bern: International Potash Institute, 1983. 62p. (IPI. Bolletin, 7).

MOREIRA, R.S. Banana: teoria e prática de cultivo. Campinas: Fundação Cargill, 1999. CD ROM.

OLIVEIRA, F.H.T. et al. Desenvolvimento de um sistema para recomendação de adubação para a cultura da bananeira. Revista Brasileira de Ciência do Solo, v.29, p.131-143, 2005.
SILVA, F.C. Manual de análises químicas de solos, plantas e fertilizantes. Brasília: EMBRAPA, 1999. 370p.

TWYFORD, I.T.; WALMSLEY, D. The mineral composition of the 'Robusta' banana plant; III - Uptake and distribution of mineral constituents. Plant and Soil. v.41, n.3, p.471-491, 1974.

VITTI, C.G.; RUGGIERO, C. Aproveitamento do engaço, coração e ráquis, como fonte de nutrientes. In: SIMPÓSIO BRASILEIRO SOBRE BANANICULTURA, 1984, Jaboticabal, SP. Anais... Jaboticabal, SP: FCAV/UNESP, 1984. p.392399. 